\title{
A Distinct Visual Pathway Mediates High-Intensity Light Adaptation of the Circadian Clock in Drosophila
}

\author{
Matthias Schlichting, ${ }^{1,2}$ @Pamela Menegazzi, ${ }^{1}$ Michael Rosbash, ${ }^{2}$ and $\mathbb{C}^{-C h a r l o t t e ~ H e l f r i c h-F o ̈ r s t e r ~}{ }^{1}$ \\ ${ }^{1}$ Universität Würzburg, Neurobiology and Genetics, Am Hubland, 97074 Würzburg, Germany, and ${ }^{2}$ Howard Hughes Medical Institute and Department of \\ Biology, Brandeis University, Waltham, Massachusetts 02454
}

\begin{abstract}
To provide organisms with a fitness advantage, circadian clocks have to react appropriately to changes in their environment. Highintensity (HI) light plays an essential role in the adaptation to hot summer days, which especially endanger insects of desiccation or prey visibility. Here, we show that solely increasing light intensity leads to an increased midday siesta in Drosophila behavior. Interestingly, this change is independent of the fly's circadian photoreceptor cryptochrome and is solely caused by a small visual organ, the HofbauerBuchner eyelets. Using receptor knock-downs, immunostaining, and recently developed calcium tools, we show that the eyelets activate key core clock neurons, namely the $s-\mathrm{LN}_{\mathrm{v}} \mathrm{s}$, at HI. This activation delays the decrease of PERIOD (PER) in the middle of the day and propagates to downstream target clock neurons that prolong the siesta. We show a new pathway for integrating light-intensity information into the clock network, suggesting new network properties and surprising parallels between Drosophila and the mammalian system.
\end{abstract}

Key words: circadian clock; Drosophila; photoreceptor

\section{Significance Statement}

The ability of animals to adapt to their ever-changing environment plays an important role in their fitness. A key player in this adaptation is the circadian clock. For animals to predict the changes of day and night, they must constantly monitor, detect and incorporate changes in the environment. The appropriate incorporation and reaction to high-intensity (HI) light is of special importance for insects because they might suffer from desiccation during hot summer days. We show here that different photoreceptors have specialized functions to integrate low-intensity, medium-intensity, or HI light into the circadian system in Drosophila. These results show surprising parallels to mammalian mechanisms, which also use different photoreceptor subtypes to respond to different light intensities.

\section{Introduction}

Circadian clocks have evolved to allow animals and plants to predict the changes of day and night and thereby increase their fitness (Daan and Tinbergen, 1980; DeCoursey et al., 2000). A crucial property of circadian clocks is the ability to adjust their physiology and behavior to light-dark cycles, in a process called entrainment (Golombek and Rosenstein, 2010).

\footnotetext{
Received June 12, 2018; revised Dec. 13, 2018; accepted Dec. 17, 2018.

Author contributions: M.S. wrote the first draft of the paper; M.S., P.M., M.R., and C.H.-F. edited the paper; M.S., M.R., and C.H.-F. designed research; M.S. and P.M. performed research; M.S. and P.M. analyzed data; M.S., M.R., and C.H.-F. wrote the paper.

The work was supported by the Howard Hughes Medical Institute and German Research Foundation (DFG) projects A2 and A1 of the Collaborative Research Center (SFB1047). M.S. was further sponsored by a Hanns-Seidel Excellence Grant sponsored by the Federal Ministry of Education and Research and a DFG research scholarship (SCHL2135 1/1). We thank Ralf Stanewsky and Jaga Giebultowicz for providing antibodies and Martin Heisenberg and Claude Desplan for providing fly strains. Stocks obtained from the Bloomington Drosophila Stock Center, which is funded by the National Institutes of Health (Grant P400D018537), were used in this study.

The authors declare no competing financial interests.

Correspondence should be addressed to Matthias Schlichting at mschlichting@brandeis.edu.

https://doi.org/10.1523/JNEUROSCI.1497-18.2018

Copyright $\odot 2019$ the authors $\quad 0270-6474 / 19 / 391621-10 \$ 15.00 / 0$
}

In all clock cells, the transcriptional-translational feedback loop is believed to underlie these circadian rhythms of behavior. In short, Clock and Cycle activate period (per) and timeless (tim) transcription, respectively. PER and TIM proteins accumulate in the early night, reenter the nucleus toward the end of the night, and inhibit their own transcription (Hardin et al., 1990; Sehgal et al., 1994; Allada et al., 1998; Rutila et al., 1998).

In mammals, the circadian photoreceptor melanopsin in the retinal ganglion cells, as well as the rods and cones of the visual system, can transduce light information into the central brain clock, the suprachiasmatic nucleus (Ebihara and Tsuji, 1980; Berson et al., 2002; Hattar et al., 2002). Similarly, flies can use the circadian photoreceptor cryptochrome (CRY) within most of the clock neurons as well as their visual system to synchronize their clock (Stanewsky et al., 1998; Rieger et al., 2003; Benito et al., 2008; Yoshii et al., 2008). The latter consists of the two compound eyes, three ocelli, and two Hofbauer-Buchner (HB) eyelets (Hofbauer and Buchner, 1989).

The clock neurons determine the diurnal behavior pattern of the fly. In light-dark (LD) cycles, flies show a bimodal locomotor 
activity pattern with a morning (M) peak and an evening (E) peak, which are clearly separated by a siesta. Essential groups of lateral neurons include the $s-\mathrm{LN}_{\mathrm{v}} \mathrm{s}$, which are important for morning anticipation ( $\mathrm{M}$ activity) and are often referred to as $\mathrm{M}$ cells (Grima et al., 2004; Stoleru et al., 2004). The $1-\mathrm{LN}_{\mathrm{v}} \mathrm{s}$ are important arousal centers (Shang et al., 2008). Additional circadian lateral neurons include three CRY-positive $\mathrm{LN}_{\mathrm{d}} \mathrm{s}$, which dictate the $\mathrm{E}$ peak and are referred to as $\mathrm{E}$ cells.

In vitro experiments have investigated the connection of the visual system to the clock network. Whereas the compound eyes appear to be contacting the $1-\mathrm{LN}_{\mathrm{v}} \mathrm{s}$ via cholinergic interneurons, the $\mathrm{HB}$ eyelets directly innervate the accessory medulla and increase $\mathrm{Ca}^{2+}$ and cAMP in the $\mathrm{s}-\mathrm{LN}_{\mathrm{v}} \mathrm{s}$ upon stimulation (Muraro and Ceriani, 2015; Schlichting et al., 2016). However, it is not understood how the visual system affects the rest of the central brain clock or how different light intensities affect these connections.

Studies in mammals and flies show that a complex visual system is required to adjust an animal clock to the light environment (Foster and Helfrich-Förster, 2001). At low intensity (LI), entrainment is predominantly performed by retinal rods, whereas melanopsin takes over at $\mathrm{HI}$ due to the saturation of the visual system by light (Lall et al., 2010; Lucas et al., 2012). In Drosophila, CRY is important for detecting LI due to its photon-integrating function (Vinayak et al., 2013) and four of the five rhodopsinexpressing photoreceptors of the compound eyes mediate entrainment at LI to moderate irradiances (Saint-Charles et al., 2016). Photoreception for HI is still unknown. However, flies lacking the whole visual system, as well as CRY, are unable to entrain to LD regimes of moderate light intensity (HelfrichFörster et al., 2001).

In this study, we investigate how $\mathrm{HI}$ changes fly behavior and how it is incorporated into the clock network. HI significantly increases the fly siesta by delaying the E-activity onset. This phenotype is independent of CRY and the compound eyes, but does require the HB eyelets. We further show that the release of acetylcholine significantly increases in vivo $\mathrm{Ca}^{2+}$ and neuronal activity of the eyelet target neurons, the s- $\mathrm{LN}_{\mathrm{v}} \mathrm{s}$. Our data further suggest that HI delays PER degradation in the $s-\mathrm{LN}_{\mathrm{v}} \mathrm{s}$ during the day. This change propagates throughout the network to change PER cycling of downstream target neurons, such as the $\mathrm{DN}_{1} \mathrm{~s}$, which have been implicated in the control of the siesta (Guo et al., 2016).

\section{Materials and Methods}

\section{Fly strains}

The following fly strains have been described previously and were used in this study: $\mathrm{WT}_{\mathrm{CS}}, \mathrm{WT}_{\mathrm{ALA}}$ (Sandrelli et al., 2007), $\mathrm{WT}_{\mathrm{LB}}$ (Schlichting et al., 2014), $w^{1118}, c r y^{01}$ (Dolezelova et al., 2007), $c l^{\text {eya }}$ (Bonini et al., 1993), rh6 ${ }^{1}$ (Cook et al., 2003), $r h 5^{2}$ (Yamaguchi et al., 2008), ninaE ${ }^{17}$ (Kumar and Ready, 1995), sev ${ }^{\text {LY3 }}$, cli $i^{\text {eya }}$; rh6 ${ }^{1}$, norpA ${ }^{\mathrm{P} 24}$, nocte (Glaser and Stanewsky, 2005) $h d c^{\mathrm{KK} 910}$ (BL 64203), R6-GAL4 (Helfrich-Förster et al., 2007), UAS-mAchRA-RNAi (BL 44469, 27571), UAS-nAChR-RNAi (BL 31883, 28688), pdf-GS-GAL4 (Depetris-Chauvin et al., 2011), ActPMKII::GAL4DBDo, ActP-p65AD::CaM (UAS-Tric) (Gao et al., 2015), and UAS-GFPS65T (BL 1522). All experiments were performed in male flies.

\section{Behavior recording}

Regensburg system. Individual 2- to 5-d-old male flies were transferred into photometer half-cuvettes with water and sugar supply. The fly's activity was measured as IR beam crosses caused by the fly in 1 min intervals. Independent sets of flies were tested at LI $(\sim 10$ lux, 1 week duration) or HI ( $\sim 10.000$ lux, 1week duration). Independent sets of flies were used to exclude behavioral effects due to aging.
Würzburg system. Individual 2- to 5-d-old male flies were placed into glass tubes containing food ( $2 \%$ agarose, $4 \%$ sucrose). These glass tubes were placed in Drosophila activity monitors (DAMs) and the activity of the flies was measured in $1 \mathrm{~min}$ intervals. Flies were entrained for 1 week at LI ( $\sim 10$ lux $)$ followed by 1 week of HI ( $\sim 8000$ lux $)$. We were only able to reach 8000 lux due to a different position of the LEDs using the DAM system. Both light intensities were investigated within the same flies to follow changes in behavior within individual flies. All experiments were conducted within light boxes in climate-controlled chambers at a temperature of $20^{\circ} \mathrm{C}$. To minimize fluctuations in temperature, each light box was equipped with a fan to constantly exchange the air within the light box.

\section{Behavior analysis}

All data were plotted as actograms using ActogramJ (Schmid et al., 2011). Subsequently, we calculated average activity and average sleep profiles using the last $4 \mathrm{~d}$ of each light condition as described previously (Schlichting and Helfrich-Förster, 2015). Sleep was measured as intervals of at least 5 min of inactivity. To determine the timing of $\mathrm{M}$ and $\mathrm{E}$ activity and onset/offset, we generated single-fly average days in $30 \mathrm{~min}$ bins. We then determined fly by fly the first time point when a fly's activity reached the siesta activity amount as the offset of $\mathrm{M}$ activity and the first time point of increased activity beyond siesta levels as E-peak onset. This analysis was done blindly by two independent investigators and we calculated the average value \pm SEM. We further calculated a performance index (PI) to determine the flies' E-peak onset to overcome subjective determination of E-peak onset. The PI is calculated as follows: $\mathrm{PI}=$ sum of activity 3-6 h before E peak HI/sum of activity 3-6 h before E peak LI. A PI $<1$ indicates a reduction of activity, which we interpret as a delay in E-peak onset. Data were compared using a Student's $t$ test or a one-way $t$ test comparing the PI with the value 1.

\section{Immunostaining and confocal microscopy}

Fifteen to 20 male flies were fixed in 4\% PFA in PBST $(0.5 \%$ Triton $\mathrm{X}-100$ ) for $2 \mathrm{~h}$ and $45 \mathrm{~min}$ and subsequently rinsed with $0.5 \%$ PBST $4 \times$ 10 min each. Brains were dissected in PBST and blocked in 5\% NGS in PBST for 3 h. Primary antibodies were applied overnight at RT. The following antibodies were used: rabbit anti-PER (1:1000, provided by R. Stanewsky; Stanewsky et al., 1997), rat anti-TIM (1:1000, provided by J. Giebultowicz), mouse anti-pigment dispersing factor (anti-PDF, 1:2000, DSHB), and chicken anti-GFP (1:1500, Abcam). After rinsing $5 \times 10 \mathrm{~min}$ each with PBST, secondary antibodies (Invitrogen) were applied for $3 \mathrm{~h}$ at room temperature. After washing the brains $5 \times 10$ in PBST, brains were mounted on glass slides using Vectashield mounting medium.

For comparing PER and TIM profiles at LI and HI, CS and $c l i{ }^{\text {eya }}$; $r h 6^{1}$ flies were entrained to the respective light intensity for $5 \mathrm{~d}$ and collected around the clock in $2 \mathrm{~h}$ intervals. For imaging the dorsal arborizations, CS and $r h 6^{1}$ flies were entrained at the standard LD regime and collected at ZT6. To evaluate neuronal activity at LI and HI, pdfGS $>$ Tric $>$ GFP flies were raised on standard cornmeal medium. Male flies between 2 and $5 \mathrm{~d}$ after eclosion were transferred on agar $(2 \%$ agar, $4 \%$ sugar, and $200 \mu \mathrm{g} / \mathrm{ml} \mathrm{Ru} 486$ ) and entrained for $3 \mathrm{~d}$ in $\mathrm{LD}$ 12:12 at LI and HI, respectively.

All brains were imaged using a Leica SPE or Leica SP5 confocal microscope in $2 \mu \mathrm{m}$ sections. All settings were kept constant within the experiment. Staining intensity was determined by measuring the brightest 9 pixels of the cell of interest minus 3 different background intensities as described previously (Menegazzi et al., 2013).

\section{Results}

HI light delays the evening peak and lengthens the siesta

To investigate the effect of light intensity on fly behavior, we subjected three different WT strains to light dark cycles of LI and HI white light. All flies displayed the classic bimodal activity pattern with an M peak and an E peak of activity. These peaks were clearly separated by a siesta, during which flies tend to sleep (Fig. 1A). We did not observe any consistent changes in M- or E-peak amplitude or timing. 

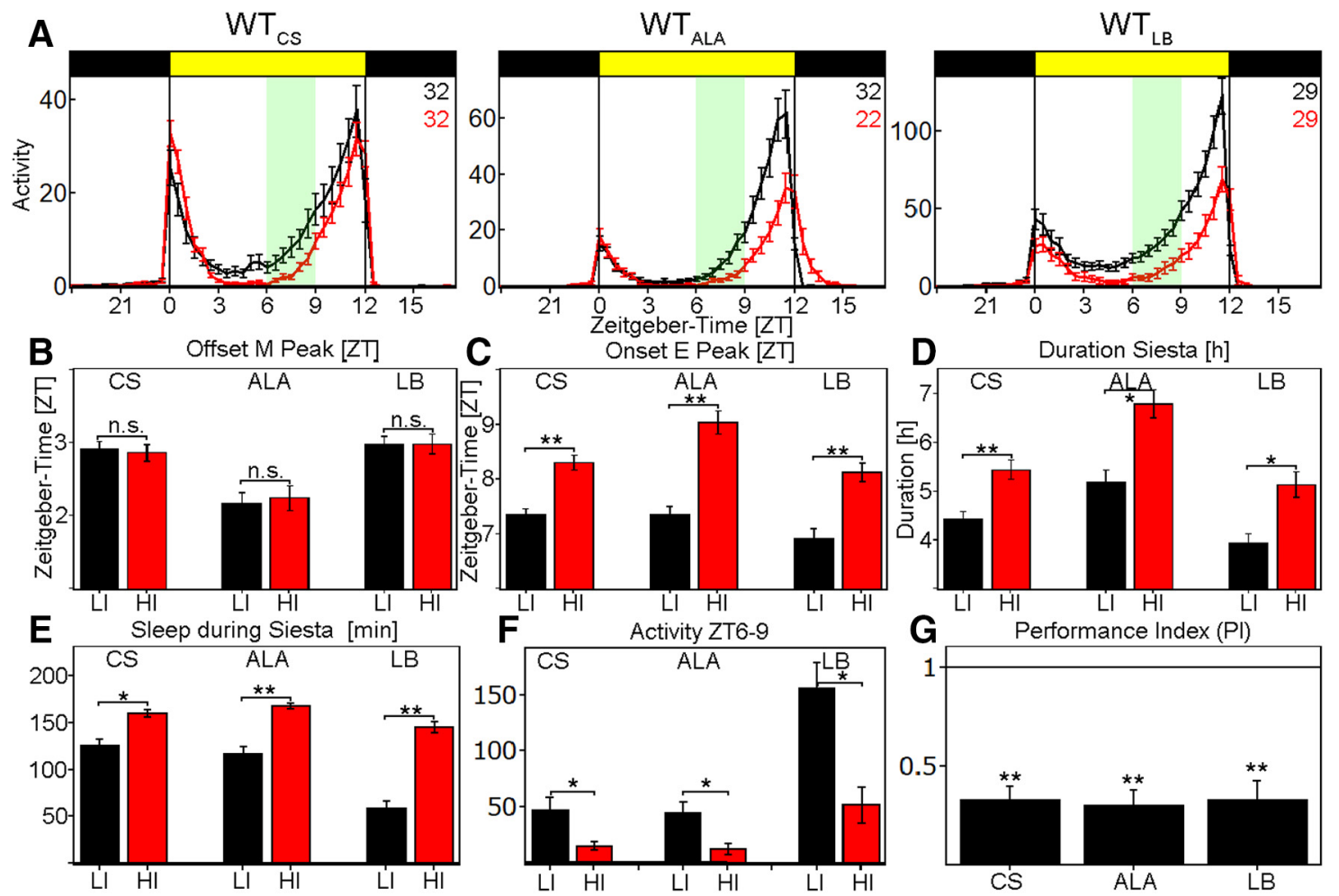

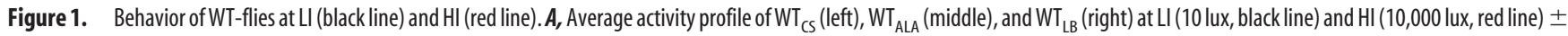
SEM recorded in the Regensburg system. All flies show a bimodal activity pattern with reduced activity during the siesta. $\boldsymbol{B}$, Quantification of M-peak offset at LI (black) and HI (red) in ZT \pm SEM. All strains show a M-peak offset $\sim 2-3$ h after lights on, but do not change the onset upon $\mathrm{HI}_{\text {( }} \mathrm{WT}_{\mathrm{CS}}: p=0.9379, \mathrm{WT}_{\mathrm{ALA}}: p=0.1859, \mathrm{WT}_{\mathrm{LB}}: p=0.3862$ ). C, Quantification of E-peak onset at LI (black) and $\mathrm{HI}$ (red) in ZT \pm SEM. All flies significantly delay the E-peak onset by $\sim 1 \mathrm{~h}$ upon $\mathrm{HI}$ simulation $(p<0.0001$ for all genotypes). $D$, Duration of siesta in hours \pm SEM. All flies show a significantly longer siesta at HI compared with LI (WT $\mathrm{WS}_{\mathrm{CS}} p=0.0001, \mathrm{WT}_{\mathrm{ALA}}: p=0.0015, \mathrm{WT}_{\mathrm{LB}}: p=0.0012$ ). $\mathrm{E}$, Total sleep amount at LI (black) and HI (red) between ZT6 and ZT9 in minutes \pm SEM. All flies significantly increase their sleep amounts at $\mathrm{HI}\left(\mathrm{WT}_{\mathrm{CS}}: p=0.0014, \mathrm{WT}_{\mathrm{ALA}}: p<0.0001, \mathrm{WT}_{\mathrm{LB}}: p<0.0001\right) . \boldsymbol{F}$, Sum of activity indicated in the green area in $A$. All flies significantly reduce their activity level at HI (WT $\mathrm{WS}_{\mathrm{C}}: P=0.0091, \mathrm{WT}_{\mathrm{ALA}}: P=0.0114, \mathrm{WT}_{\mathrm{LB}}: P=0.0006$ ). G, PI calculated by the sum of activity between ZT6 and ZT9 at HI divided by the sum of activity between ZT6 and ZT9 at LI. All genotypes show a PI significantly $<1$, which we interpret as a delayed E-peak onset $\left(p<0.0001\right.$ for all genotypes). ${ }^{*} p<0.05,{ }^{* *} p<0.001$.

We then considered the shape of the activity profiles. Upon careful inspection, all WT strains appeared to lengthen their siesta by delaying the E-peak onset by $1-2 \mathrm{~h}$, whereas the M-peak offset remained unchanged (Fig. $1 B-D$ ). This change in behavior was accompanied by significantly reduced activity levels between ZT6 and ZT9 (green boxes in Fig. 1 A,F). We calculated a PI from the activity levels during this period. A PI $<1$ represents a reduction of activity at $\mathrm{HI}$, whereas a $p>1$ represents an increase. Because the PI is a more objective measurement of the E-peak onset, we focused on this value throughout the study. All WT strains showed a significant reduction of activity, which we interpret as a delayed E-activity onset (Fig. $1 G$ ). One explanation for this behavior is that $\mathrm{HI}$ induces a longer midday siesta. To address this possibility, we calculated sleep levels in all WT strains. Indeed, HI significantly increased the amount of sleep during the siesta by at least $30 \mathrm{~min}$ (Fig. $1 E$ ). HI therefore delayed the $\mathrm{E}$ activity onset by lengthening the siesta and increasing sleep amounts.

\section{HB eyelets mediate light-intensity integration}

To test which light input pathway mediates this siesta response, we analyzed the behavior of several photoreceptor mutants. $C r y^{01}$ flies, like WT, showed a bimodal behavior with $\mathrm{M}$ and $\mathrm{E}$ peaks around lights on or lights off, respectively (Fig. 2A). The mutant strain also responded to $\mathrm{HI}$ similarly if not identically to the WT strain: it significantly delayed the onset of E activity ( $p<$ 0.0001 ; Fig. $2 B)$ and showed a PI significantly $<1(p<0.0001$;
Fig. 2C). These results suggest that $\mathrm{HI}$ responses are not mediated via CRY.

We also investigated mutants affecting the fly visual system. We first used the $\mathrm{cli}^{\text {eya }}$ mutant strain to investigate the contribution of the compound eyes for several reasons: (1) the mutant showed no residual eye structures; (2) we previously showed that ocelli and HB eyelets are still intact (Schlichting et al., 2014), and (3) several circadian studies have previously characterized this strain. As in earlier studies, $c i^{\text {eya }}$ mutants showed a significantly reduced M-peak amplitude, as well as an advanced $\mathrm{E}$ peak in both LD conditions (Fig. 2A). A comparison between LI and $\mathrm{HI}$ in this strain indicated that HI still exhibits a delay of $\mathrm{E}$ activity onset $(p<0.0001$; Fig. $2 B)$ and a PI significantly $<1$ in response to HI $(p<0.0001$; Fig. $2 C)$. This suggests that the siesta and E peak phenotypes are independent of the compound eyes.

We then investigated the effect of the HB eyelets. Because the lack of specific drivers precluded manipulating the eyelets without perturbing the compound eyes, we examined the effect of the $r h 6^{1}$ mutant. The mutation eliminates the photopigment of the eyelets but also of $70 \%$ of R 8 in the compound eyes (Sprecher and Desplan, 2008). The mutant exhibited a reduced M-peak amplitude and an advanced E peak under both LI and HI light (Fig. $2 A)$. Importantly, the profiles did not differ between LI and HI light: they neither delayed the onset of $\mathrm{E}$ activity ( $p=0.2885$; Fig. $2 B$ ) nor significantly reduced the PI from 1 ( $p=0.5619$; Fig. $2 C$ ).

To verify that the effect is solely visible in $r h 6^{1}$ mutant flies, we monitored the behavior of several other rhodopsin mu- 

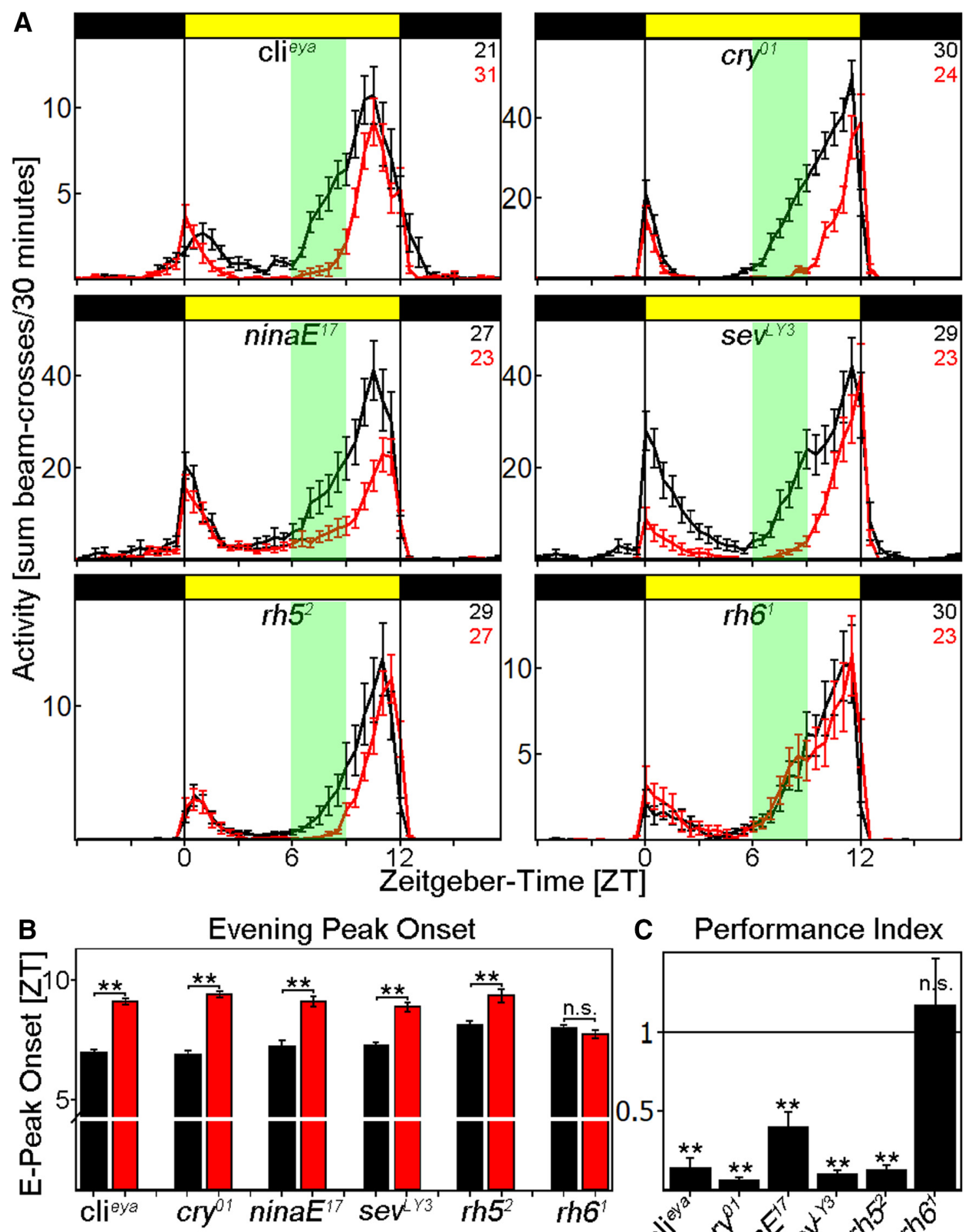

C Performance Index

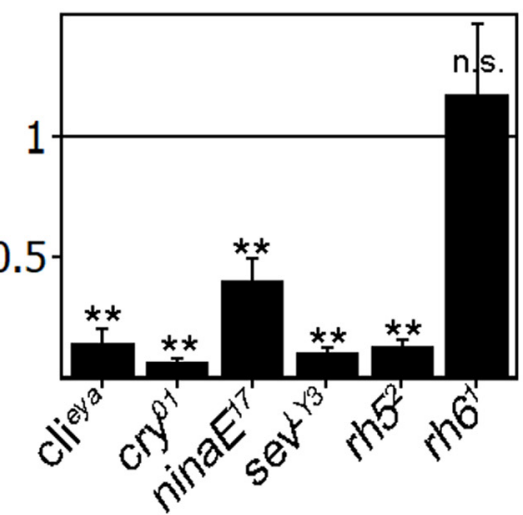

Figure 2. Behavior of photoreceptor mutants at LI and HI. A, Average activity profiles of flies exposed to LI (black line) and HI (red line) \pm SEM using the Regensburg system. Flies deficient of either compound eyes ( $\left(\mathrm{Cl}^{\mathrm{eya}}\right)$ or $\mathrm{CRY}\left(\mathrm{Cry}^{01}\right)$ behave similar to $\mathrm{WT}_{\mathrm{CS}}$, whereas the loss of rhodopsin 6 renders the flies insensitive to light-intensity changes. Consistent with the li $^{\text {eya }}$ data, flies affecting the compound eyes (ninaE ${ }^{17}$, sev ${ }^{\mathrm{LY} 3}$, and $r h 5^{2}$ ) behave like WT $\mathrm{CS}$. B, Determination of E-activity onset for all photoreceptor mutants. Cli ${ }^{\text {eya }}, \mathrm{Cry}^{01}$, ninaE ${ }^{17}$, sev ${ }^{\mathrm{LY} 3}$, and $r h 5^{2}$ flies

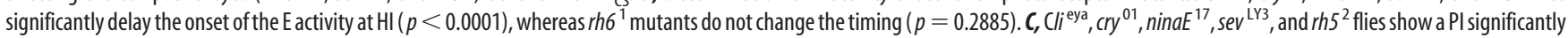
$<1\left(p<0.0001\right.$ for all), whereas the Pl of $r h 6^{1}$ flies is indistinguishable from $1(p=0.5619)$. ${ }^{*} p<0.001$.

tants under LI and HI conditions: ninaE $E^{17} \operatorname{sev}^{\mathrm{LY} 3}$, and $r h 5^{2}$. They all significantly delayed the E-peak onset $(p<0.0001$; Fig. $2 A, B)$ and decreased their activity between ZT6 and ZT9 at $\mathrm{HI}$ as WT flies did, resulting in a PI significantly $<1(p<$ $0.0001)$.
To exclude the possibility that heating of the flies at $\mathrm{HI}$ is the reason for the observed siesta phenotype, we tested nocte flies, which were previously shown to be deficient in temperature entrainment (Glaser and Stanewsky, 2005). As expected, these flies still showed a PI significantly $<1(P I=0.25 \pm 0.06, p<0.0001)$, 

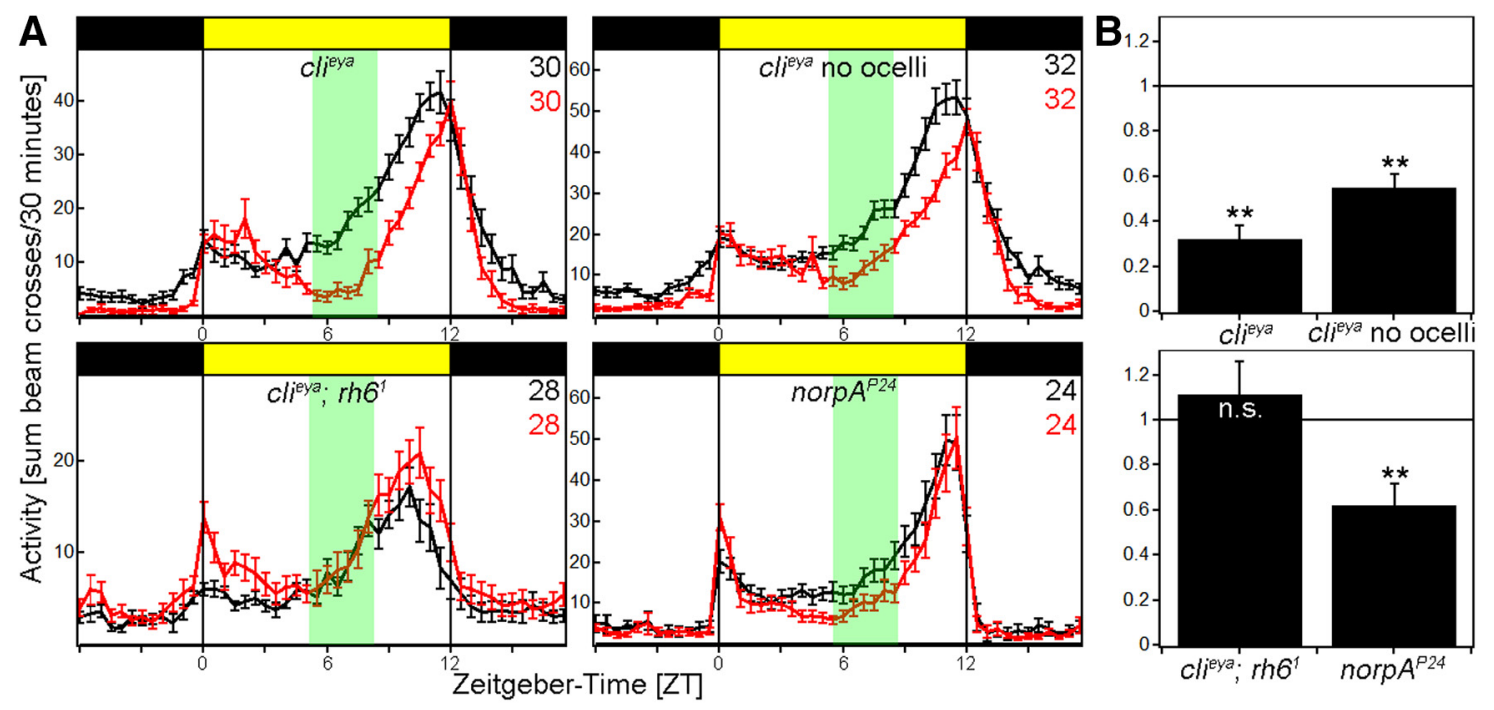

Figure 3. Behavior of photoreceptor mutants at $L$ l and HI. A, Average activity profiles of flies exposed to LI (black line) and HI (red line) \pm SEM using the Würzburg system. Flies deficient of either compound eyes ( $\left(\mathrm{li}^{\text {eya }}\right.$ ) or compound eyes and ocelli ( $\left(\mathrm{l}^{\text {eya }}\right.$ no ocelli) and flies lacking norpA $\left(\right.$ norpA $\left.{ }^{\mathrm{P2}}\right)$ still react to $\mathrm{Hl}$, whereas the loss of rhodopsin 6 in cli ${ }^{\text {eya }}$ background renders the flies insensitive to light-intensity changes. $\boldsymbol{B}$, cli ${ }^{\text {eya }}$, cli ${ }^{\text {eya }}$ no ocelli and norpA ${ }^{\text {P24 }}$ flies show a PI significantly $<1$ (cli ${ }^{\text {eya }}$, cli ${ }^{\text {eya }}$ no ocelli: $p<0.0001$, norpA $\left.^{\text {P24 }}: p=0.0014\right)$, whereas the PI of $c^{\text {eya }}$; rh6 ${ }^{1}$ is indistinguishable from $1(p=0.4613)$. ${ }^{* *} p<0.001$.

suggesting that light input is the source for the change in behavior (data not shown).

$\mathrm{Cli}^{\text {eya }}$ mutant flies still have working ocelli and $\mathrm{HB}$ eyelets. To address the possibility of the ocelli contributing to HI entrainment, we painted the ocelli of $\mathrm{cli}^{\text {eya }}$ mutant flies to eliminate their function. $\mathrm{Cli}^{\text {eya }}$ mutants with painted ocelli showed a significantly delayed E-peak onset and a PI significantly $<1$ at HI indistinguishably from $\mathrm{cli}^{\text {eya }}$ mutants with functional ocelli (Fig. $3 A, B$, top). This suggests that the ocelli do not or only marginally contribute to $\mathrm{HI}$ entrainment.

We further created $\mathrm{Cli}^{\mathrm{eya}}$; $r h 6^{1}$ mutants to eliminate $\mathrm{HB}$ eyelet function in $\mathrm{cli}^{\text {eya }}$ background. These flies reproduced the $r h 6^{1}$ mutant phenotype: flies showed a reduced M-peak amplitude and an advanced E peak compared with WT flies in both light conditions; they also did not delay their E-peak onset at $\mathrm{HI}$ as evident by their PI, which was not different from 1 (Fig. $3 A, B$, bottom). These data further suggest that the $\mathrm{HB}$ eyelet is principally responsible for the adaptation to HI.

Rh6-positive photoreceptors were recently shown to use a norpA-independent phototransduction pathway (Ogueta et al., 2018). To address this issue, we monitored the behavior of nor$p A^{\mathrm{P} 24}$ flies at LI and HI. These mutant flies had a PI significantly $<1$ similar to WT flies (Fig. $3 A, B$, bottom), implicating the newly discovered norpA-independent pathway in the $\mathrm{HB}$ eyelets as being involved in mediating the adaptation to HI.

\section{Acetylcholine mediates signal transduction to clock cells}

The $\mathrm{HB}$ eyelets signal to the $\mathrm{s}-\mathrm{LN}_{\mathrm{v}} \mathrm{s}$ via acetylcholine, whereas they appear to signal to the $1-\mathrm{LN}_{\mathrm{v}} \mathrm{s}$ via histamine (Schlichting et al., 2016). We therefore investigated which of these two neurotransmitters transduces light-intensity information to the clock neuron network. As described previously, flies unable to synthesize histamine $\left(h d c^{\mathrm{JK} 910}\right)$ showed a reduced $\mathrm{M}$ peak as well as an advanced E peak (Fig. $4 A$, top), but they also showed a PI significantly $<1$ ( $p=0.0012$; Fig. $4 B$, top); this suggests that histamine is not necessary for siesta adaptation to HI. Because histamine is the only neurotransmitter of the compound eyes (Pollack and Hofbauer, 1991), this agrees with the previous $\mathrm{cli}^{\text {eya }}$ data (Figs. 2A, 3A).
Acetylcholine plays a key role as an excitatory neurotransmitter in mammals and insects and the Drosophila genome encodes 10 nicotinic acetylcholine receptor subunits $(\alpha 1-\alpha 7$ and $\beta 1-\beta 3)$; subpopulations of these subunits are implicated in Drosophila behavior. In addition, the genome encodes two muscarinic acetylcholine receptors ( $m A \operatorname{ch} R A$ and $m A \operatorname{ch} R B)$. To investigate the contribution of these receptors to light-intensity integration, we expressed RNAi constructs against specific receptors or receptor subunits in the s- $\mathrm{LN}_{\mathrm{v}} \mathrm{s}$ with the R6-GAL4 driver.

We tested RNAi lines against two of the 10 existing $n A c h R$ subunits (Fig. 4A, B, bottom), and all flies showed a PI $<1(p<$ 0.001 ). In contrast, knocking down $m A$ chRA completely reproduced the behavior of $r h 6^{1}$ mutants. Knock-down flies showed a significantly reduced $\mathrm{M}$-peak amplitude and a significantly advanced $\mathrm{E}$ peak compared with both parental controls (Fig. 4A). Similar results were obtained in two independent RNAi lines (Fig. $4 A$, middle). These data suggest that mAchRA acts in the $s-L_{v} s$ to integrate cholinergic input. Interestingly, RNAsequencing data suggest that the $s-\mathrm{LN}_{\mathrm{v}} \mathrm{s}$ are selective: whereas $m A C h R A$ is expressed in all circadian subpopulations investigated, only the PDF cells specifically exclude $m A \operatorname{ch} R B$ expression, indicating an important role of $m A \operatorname{ch} R A$ in these neurons (Fig. 4D; Abruzzi et al., 2017).

mAchRA is coupled to $\mathrm{G}_{\mathrm{q} / 11}$ and interacts with IP3/Ca ${ }^{2+} \mathrm{sec}$ ond messenger pathways (Ren et al., 2015). Because previous dissected brain imaging experiments showed increased $\mathrm{Ca}^{2+}$ in the $\mathrm{s}-\mathrm{LN}_{\mathrm{v}} \mathrm{s}$ when the $\mathrm{HB}$ eyelets were artificially activated using the P2X2 system (Schlichting et al., 2016), we expressed TRICGFP in PDF neurons (Gao et al., 2015), a transcriptional reporter surrogate for $\mathrm{Ca}^{2+}$. To avoid expression during development and express Tric-GFP only in the adult, we used the gene-switch system ( $p d f$-GS-GAL4) and measured GFP intensity in the s- and $1-\mathrm{LN}_{\mathrm{v}} \mathrm{s}$ separately after exposing the flies to LD 12:12 of LI or HI for $3 \mathrm{~d}$. There was no significant difference between LI and HI in the $1-\mathrm{LN}_{\mathrm{v}} \mathrm{s}$, but a 2 -fold increase of GFP in the $\mathrm{s}-\mathrm{LN}_{\mathrm{v}} \mathrm{s}$ with $\mathrm{HI}$, suggesting that the eyelets activate the $s-\mathrm{LN}_{\mathrm{v}} \mathrm{s}$ at $\mathrm{HI}$ in vivo (Fig. 4C).

An increase in $\mathrm{Ca}^{2+}$ can reflect either an increase in intracellular signaling and/or an increase in neuronal activity. To address 

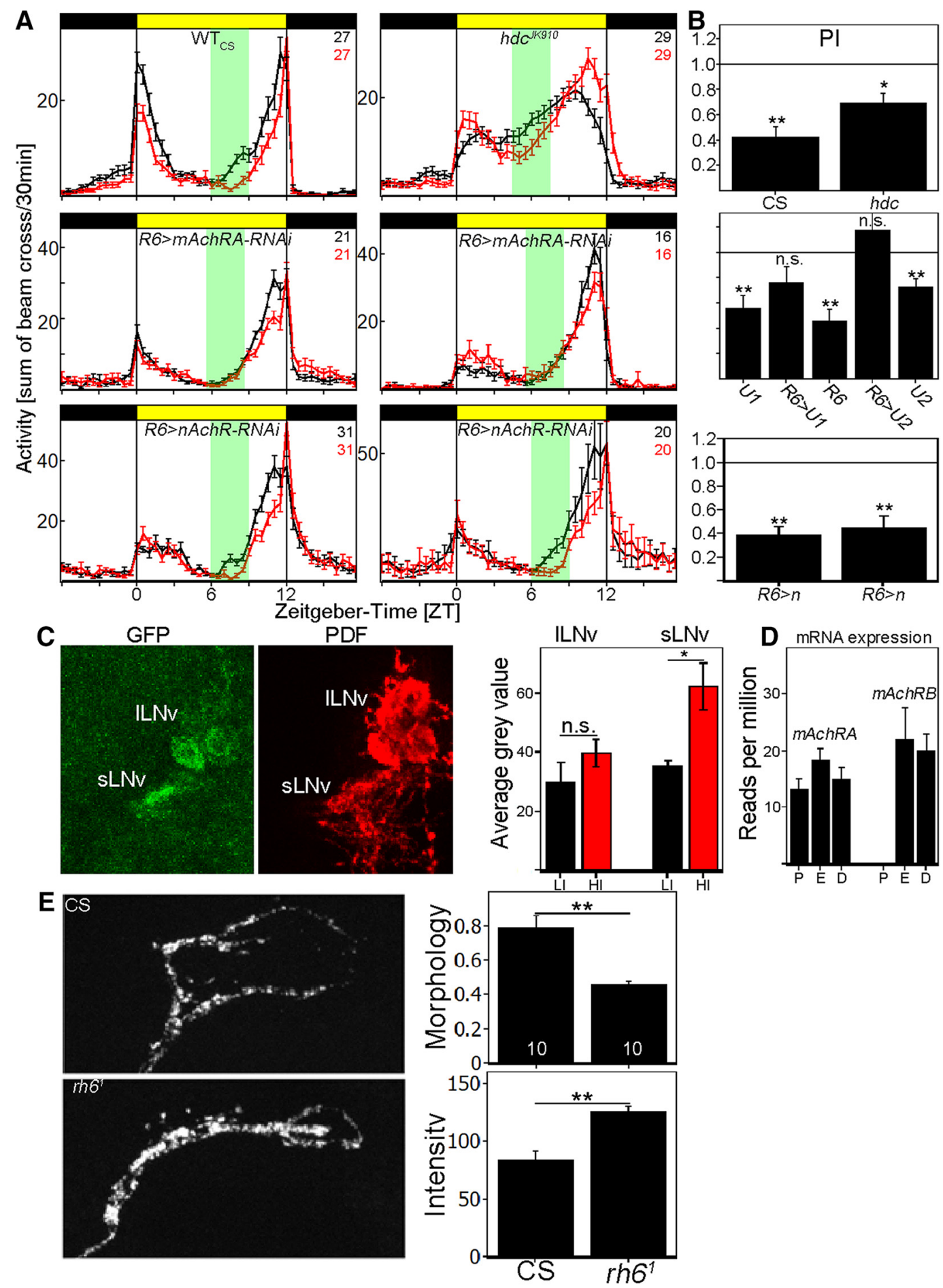

Figure 4. Cholinergic input to $s-L_{v} s$ is responsible for HI adaptation. A, Average activity profiles at LL (black line) and HI (red line) \pm SEM measured in the Würzburg system. Top, Average activity profile of WT ${ }_{C S}$ and the $h d c^{\mathrm{J} 910}$ mutant at $\mathrm{LI}$ (black line) and $\mathrm{HI}$ (red line) \pm SEM. Flies deficient of histamine synthesis are still reacting to HI by a reduction of activity. Middle, Average activity profiles of $m A c h R A$ (BL: 27571; left) and $m A$ chRA (BL:44469) knock-down in sLN ${ }_{v} s$ (right) at LI (black line) and HI (red line) \pm SEM. Knock-down of $m A$ chRA in the sLN s $_{v}$ reproduces $r h 6{ }^{1}$-mutant phenotype. The activity profiles do not differ between LI and HI. Bottom, Average activity profiles of 2 independent $n A c h R$ (left: BL 28688, right: BL 31883) knock-down in sLNvs at LI (black line) and HI (red line) \pm SEM. Both genotypes show a delayed E-peak onset comparable to the GAL4 control. B, PIs calculated from $A$. WT CS $_{\text {and }} h d \mathrm{dN}^{\mathrm{J} 910}$ mutants significantly reduce their PI at HI (CS: $p<0.0001$, $h d c: p=0.0012$ ). R6-GAL4 and both UAS control flies (U1: BL 27571; U2: BL 44469) show a PI significantly <1 (R6: $p<0.0001, \mathrm{U1}: p=0.0003, \mathrm{U2}: p=0.0002$ ), whereas the PI of $m$ AchRA knock-down in $s L_{v} s$ is indistinguishable from 1 (R6 $>U 1: p=0.07134, \mathrm{R} 6>\mathrm{U} 2: p=0.5529$ ). Knock-down of $n A c h R$ subunits does not affect $H I$ adaptation and results in significantly reduced $\mathrm{PI}$ values $(p<0.0001)$. C, Brain images of Pdf-GS>Tric-GFP stained against GFP and PDF. GFP expression was measured in $s-L_{v} s$ and $I-L N_{v} s$ as a correlate for $\mathrm{Ca}^{2+}$ levels in the individual neurons. $s$-LN $N_{v} s$ significantly increase GFP levels at HI, whereas there was no change in I-LN $N_{v}$ GFP levels, suggesting an increase of $\mathrm{Ca}^{2+}$ in $s-\mathrm{LN}_{\mathrm{v}} \mathrm{s}$ at HI. D, Relative AChR mRNA expression in PDF (P) cells,

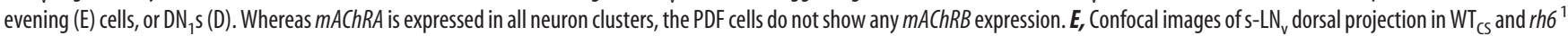

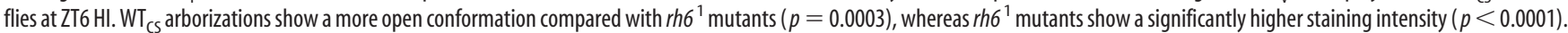
${ }^{*} p<0.05$, ${ }^{* *} p<0.001$. 

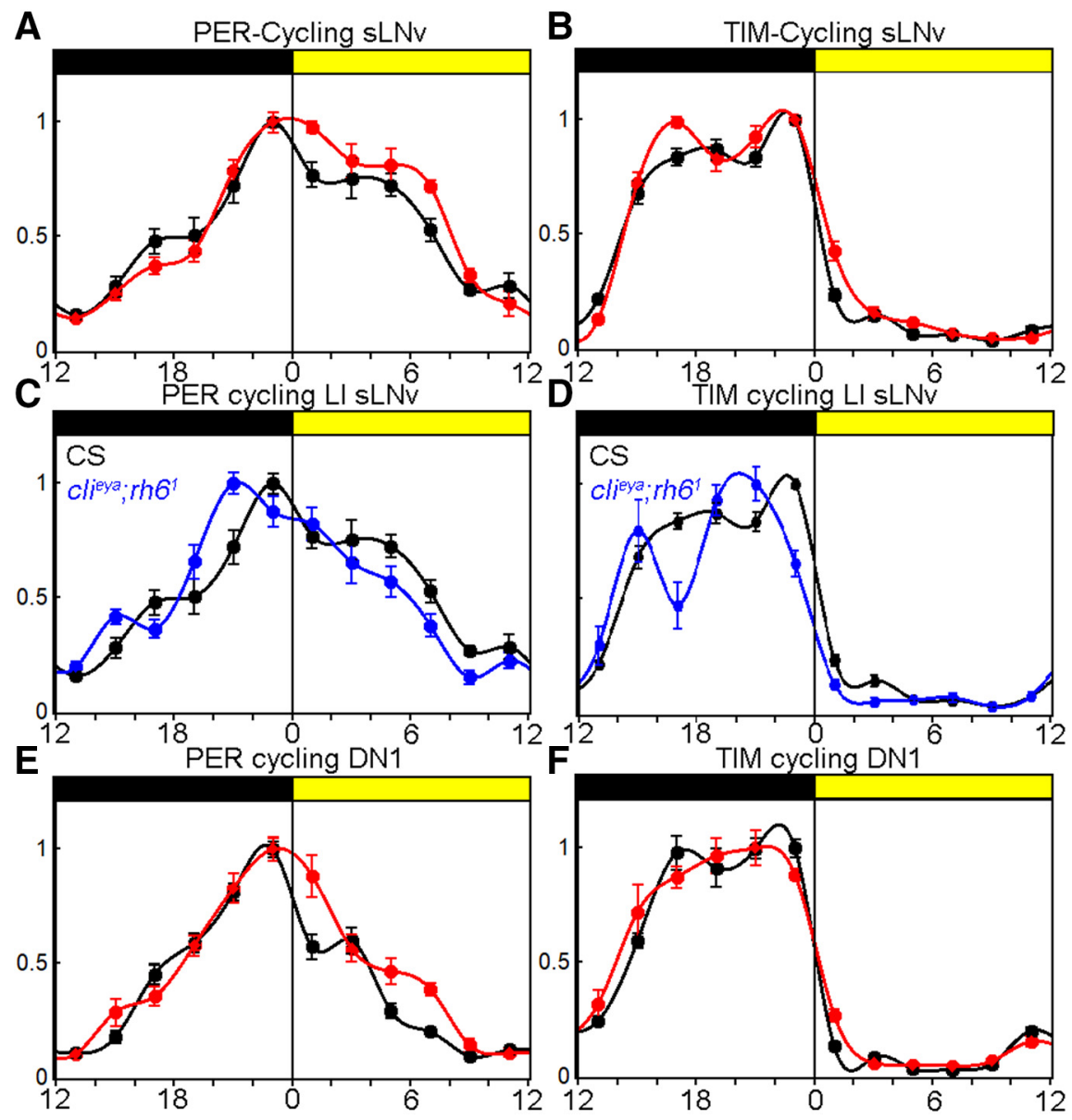

Figure 5. HI changes molecular clock synchronization. $A, S \mathrm{SN}_{v}$ PER cycling in $W \mathrm{~T}_{\mathrm{CS}}$ at $\mathrm{LI}$ (black line) and $\mathrm{HI}$ (red line) \pm SEM. PER is stabilized during the daytime at $\mathrm{HI} . \boldsymbol{B}, \mathrm{SLN}_{v}$ TIM cycling in WT $\mathrm{CS}_{\text {SS }}$ al (black line) and $\mathrm{HI}$ (red line) \pm SEM. TIM cycling is identical in both conditions. $C$, sLN ${ }_{v}$ PER cycling in $W_{C S}$ and $c i^{\text {eya }}$; $r h 6^{1}$ mutants at LI. PER decays faster during daytime and the PER staining intensity maximum is advanced in the mutant. $D$, sLN $_{\mathrm{v}}$ TIM cycling in $\mathrm{WT}_{\mathrm{CS}}$ and cli ${ }^{\text {eya }} ;$;h ${ }^{1}$ mutants at LI. TIM cycling staining intensity maximum is advanced in the mutant. $E, \mathrm{DN}_{1}$ PER cycling in WT $\mathrm{CSS}_{\text {at }} \mathrm{LI}$ (black line) and $\mathrm{HI}$ (red line) $\pm \mathrm{SEM}$. PER is stabilized during the daytime at HI. F, TIM cycling in WT $\mathrm{CS}_{\text {at }}$ aI (black line) and HI (red line) \pm SEM. TIM cycling is identical in both conditions.

neuronal activity, we assayed the $\mathrm{s}-\mathrm{LN}_{\mathrm{v}}$ dorsal projections, which undergo daily oscillations in fasciculation and volume that reflect changes in neuronal activity: they show an open conformation in the early daytime during times of relatively high activity, whereas the conformation is closed at nighttime during times of low activity (Fernández et al., 2008; Sivachenko et al., 2013). We compared the morphology and the staining intensity of these projections between $\mathrm{WT}_{\mathrm{CS}}$ and $r h 6^{1}$ mutant strains in the middle of the day (ZT6), when they normally show an open conformation.

Indeed, the conformation appeared much more closed at ZT6 in $r h 6^{1}$ mutants (Fig. $4 E$ ). We quantified this phenotype with the complexity index, which represents the number of pixels stained by the PDF antibody divided by the circumference of the stained area; that is, a smaller index reflects a more closed conformation. We found a significantly lower complexity index in the $r h 6^{1} \mathrm{mu}-$ tants compared with WT, suggesting that the $\mathrm{s}-\mathrm{LN}_{\mathrm{v}} \mathrm{s}$ are less active in the mutant. Consistent with this interpretation, the mutants showed a significantly higher PDF staining intensity at ZT6 in the dorsal projections than the WT. Because neuronal firing is required for neuropeptide release, a higher neuropeptide level in the terminals at ZT6 also suggests less firing in the mutant.
Light input significantly alters PER, but not TIM cycling, in WT s- $\mathrm{LN}_{\mathbf{v}} \mathrm{s}$

To investigate an effect of light intensity on the molecular circadian clock, we determined PER and TIM levels in clock neurons at $2 \mathrm{~h}$ intervals in WT flies under LI and HI conditions. As expected, TIM levels were extremely low during the day, started to accumulate at the beginning of the night, and reached their maximum around ZT20 (Fig. 5B). Also, as expected, PER reached its peak levels toward the end of the night and decayed more slowly than TIM during the day (Fig. 5A). There were no differences in TIM cycling between the two light conditions, most likely due to the extreme light sensitivity of CRY (Vinayak et al., 2013). However, there were significant differences in PER cycling in the $\mathrm{s}-\mathrm{LN}_{\mathrm{v}} \mathrm{s}$ : whereas the increase of PER during the night was unaffected, PER disappeared more slowly at HI, suggesting relative PER stabilization during the daytime degradation phase. To address whether this PER stabilization is due to light input from the visual system, we compared WT PER cycling with $c l i{ }^{\text {eya }}$; rh $6^{1}$ mutants at LI (Fig. 5C). As expected, PER was destabilized during the day compared with WT flies. Most interestingly, PER and TIM staining maxima appear to be advanced by $\sim 2 \mathrm{~h}$ (Fig. $5 C$ ), which corresponds to the advanced E-peak timing in the mutant (Fig. 3C). These data suggest that light input from the visual system stabilizes $\mathrm{SLN}_{\mathrm{v}}$ PER in an intensitydependent manner.

\section{Communication with dorsal neurons mediates the delay in E-peak onset}

The $s-\mathrm{LN}_{\mathrm{v}} \mathrm{s}$ were previously shown to be essential for $\mathrm{M}$ activity and free run, but their role in governing the timing of the siesta via a delay in E-activity onset is quite unexpected. This suggests that communication of the s- $\mathrm{LN}_{\mathrm{v}} \mathrm{s}$ with downstream partners is necessary for proper siesta control and E-peak adjustment. A recent study showed that the $\mathrm{DN}_{1} \mathrm{~s}$ regulate the siesta via direct inhibition of the E cells $\left(\mathrm{LN}_{\mathrm{d}} \mathrm{s}\right.$; Guo et al., 2016). In vitro experiments showed that the $\mathrm{DN}_{1} \mathrm{~s}$ react to bath-applied PDF with an increase of neuronal firing and an increase of cAMP, similar to the positive effect of $\mathrm{HB}$ eyelet activation on the $s-\mathrm{LN}_{\mathrm{v}} \mathrm{s}$ (Seluzicki et al., 2014). In addition, the $\mathrm{s}-\mathrm{LN}_{\mathrm{v}} \mathrm{s}$ send inhibitory PDF signals to the E cells (Liang et al., 2017). Given these strong interactions between the different clock neuron clusters, we expected the same change in PER oscillations in the $\mathrm{DN}_{1} \mathrm{~s}$ such as that shown above for the $\mathrm{s}-\mathrm{LN}_{\mathrm{v}} \mathrm{s}$. Indeed, there is more PER during the day the $\mathrm{DN}_{1} \mathrm{~s}$ at $\mathrm{HI}$ (Fig. $5 E$ ). Similar to the s-LN $\mathrm{L}_{\mathrm{v}}$, TIM staining remains largely unchanged (Fig. $5 F$ ). This indicates a $\mathrm{HB}$ eyelet to $\mathrm{s}-\mathrm{LN}_{\mathrm{v}}$ to $\mathrm{DN}_{1} / \mathrm{E}$ cell connection that underlies the HI delay in the E-activity onset.

\section{Discussion}

Circadian clocks have evolved as an adaptation to the predictable changes of day and night. To optimally adjust physiology, the 


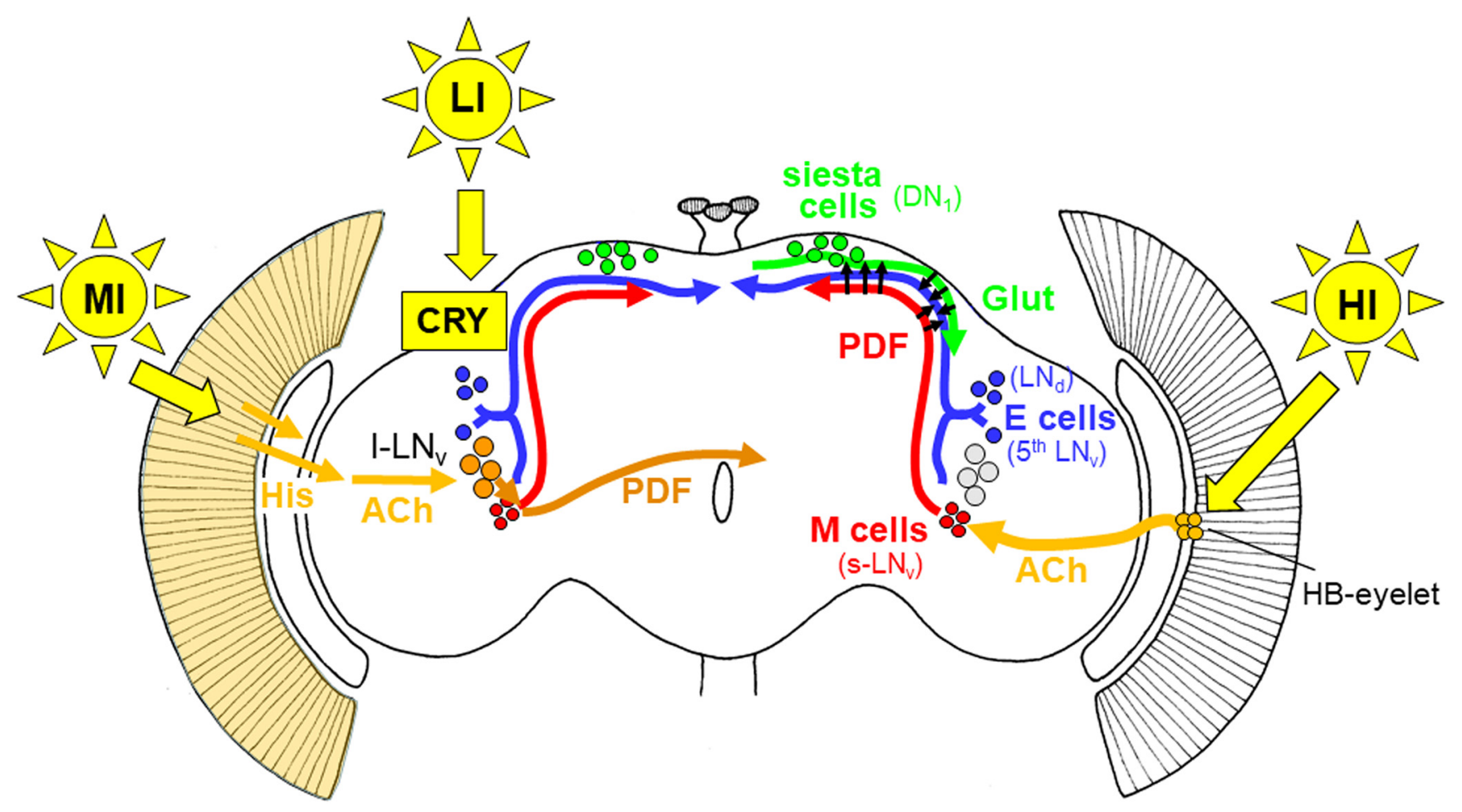

Figure 6. Model for light input to the circadian clock network of Drosophila. Ll light is sensed by CRY in the clock neurons themselves (indicated in the left brain hemisphere) and can quickly reset their oscillations to light (Vinayak et al., 2013). MI light is perceived by the compound eyes, transferred via histamine (His) to the optic lobes and via acetylcholinergic (ACh) interneurons to the large ventrolateral neurons (I-LNv; Muraro and Ceriani, 2015; indicated in the left brain hemisphere). The I-LNv signal via the neuropeptide PDF to the morning (M) and evening (E) cells, respectively (short orange arrow), and to the contralateral hemisphere (long orange arrow). The signaling of $\mathrm{Hl}$ is shown in the right hemisphere. HI light is perceived by the HB eyelets that signal via ACh to the M cells (s-LN ${ }_{\mathrm{v}}$; Schlichting et al., 2016). The M cells might signal via PDF directly to the E cells (shown by arrows) and inhibit E-cell activity or to the siesta cells (DN1) in the dorsal brain (Guo et al., 2016; Liang et al., 2017). The siesta cells then signal via glutamate (Glut) to the E cells (3 CRY-positive $L N_{d}$ and the fifth $s L N_{v}$ ) and delay the onset of E activity (Guo et al., 2016).

clock should be able to assess and respond to several external cues such as temperature, humidity and light. With respect to the latter, the clock can adapt to different levels of irradiance, at least in part to anticipate seasonal changes. Indeed, previous studies showed that the Drosophila clock is extremely light sensitive and can entrain to LD cycles of very low intensity of blue light (Vinayak et al., 2013); this is predominantly due to the photonintegrating function of CRY. In this study, we investigated the role of HI light by simulating LD cycles of 8000-10,000 lux during the day, which is comparable to the light intensity in the shade of a summer day. HI specifically alters the siesta of three WT strains; that is, the duration of the siesta increased by $\sim 1 \mathrm{~h}$ and the flies increased their amount of sleep during the day. This behavioral change was accomplished by a delay in the timing of the E-activity onset, which was accompanied by a PI $<1$, which represents a reduction of activity $3-6 \mathrm{~h}$ before the E peak at HI compared with LI, which we interpret as a delay in E-activity onset. Because all WTs show a reduction in E-peak amplitude, the PI likely reflects a combination of activity suppression and delayed E-peak onset at HI. However, the PI data correlate well with the manually determined timing of E-activity onset, making it an objective measure for fly behavior.

Communication from the $\mathrm{s}-\mathrm{LN}_{\mathrm{v}} \mathrm{s}$ is necessary for this response to $\mathrm{HI}$ and the neuropeptide PDF is likely to play an essential role. As shown in Figure 6, it is released in the dorsal part of the brain, where PDF activates a subset of dorsal clock neurons (DNs; Seluzicki et al., 2014). In particular, a subset of the $\mathrm{DN}_{1} \mathrm{~s}$ release glutamate in response to stimulation, which directly inhibits the $\mathrm{LN}_{\mathrm{d}} \mathrm{s}$, resulting in an enhanced siesta (Guo et al., 2016). In addition, PDF appears to inhibit the $\mathrm{LN}_{\mathrm{d}} \mathrm{s}$ directly (Liang et al.,
2017). In any case, the delayed onset of E activity is reproduced by adult-specific silencing of the E cells, suggesting that s- $\mathrm{LN}_{\mathrm{v}}$ firing and PDF release ultimately affect $\mathrm{LN}_{\mathrm{d}}$ firing (Guo et al., 2017).

In contrast to the CRY-dependent extreme sensitivity of the fly clock to LI light, adaptation to HI light is strictly dependent on the visual system. This result parallels the role of the visual system in adapting fly behavior to natural conditions such as twilight or moonlight (Schlichting et al., 2014, 2015). The compound eyes are clearly involved in synchronizing the clock to a wide range of light intensity and to adapt daily behavior to medium-intensity (MI) light, but by investigating different photoreceptor mutants, we excluded the compound eyes as HI sensors; neither flies lacking the eyes $\left(c i^{\text {eya }}\right)$ nor lacking the important visual system neurotransmitter histamine $\left(h d c^{\mathrm{K} 910}\right)$ fail to adapt to HI. In contrast, flies lacking Rh6 cannot respond to HI. Because this is the only rhodopsin expressed in the HB eyelets and given that the phenotype is reproduced in the $c i^{\text {eya }} r h 6^{1}$ background, the data indicate that it mediates HI light input to the clock (Sprecher and Desplan, 2008).

The HB eyelets are a major source of visual information in larvae and persist throughout the pupal stage into adulthood. They undergo changes in photopigment (Rh5 to Rh6) as well as in neurotransmitter (ACh to ACh and His) during metamorphosis and are conserved in other fly species such as the blowfly (Sprecher and Desplan, 2008). The HB eyelets directly innervate the adult accessory medulla, which is an important pacemaker center of other insects and contains dendrites of the $\mathrm{LN}_{\mathrm{v}} \mathrm{s}$ in Drosophila (Helfrich-Förster et al., 2002; Malpel et al., 2002).

Previous studies implicated the eyelets in adult entrainment. For example, flies lacking CRY and neurotransmitter output 
from the entire visual system completely fail to re-entrain to a phase delay of $6 \mathrm{~h}$, whereas functional eyelets alone allows $50 \%$ of the flies to re-entrain (Veleri et al., 2007). Similarly, our data here show that flies lacking $\mathrm{HB}$ eyelet function cannot delay the E-activity onset in response to $\mathrm{HI}$; this delay may therefore resemble a more traditional circadian phase delay.

It is interesting to contrast these results with mammalian entrainment. Very low irradiance entrainment is predominantly performed by the rods due to their high light sensitivity. The circadian photoreceptor melanopsin functions predominantly at high intensities, which saturate rod and cone signaling (Lall et al., 2010). Here, we show that there are also different pathways for LI and HI light in Drosophila: CRY mediates entrainment to extremely low irradiances, whereas the HB eyelet mediates $\mathrm{HI}$ adaptation. This suggests some similarity if not an evolutionary relationship between the $\mathrm{HB}$ eyelet and the melanopsincontaining retinal ganglion cells of mammals.

Another goal of this study was to find the neuronal pathways downstream of the eyelets. In a previous study, we showed that eyelet activation with the P2X2 system leads to increases of $\mathrm{Ca}^{2+}$ and cAMP in the s- $\mathrm{LN}_{\mathrm{v}} \mathrm{s}$ (Schlichting et al., 2016). If this connection is relevant to $\mathrm{HI}$ adaptation, then we expected to see $\mathrm{Ca}^{2+}$ increases in the s- $\mathrm{LN}_{\mathrm{v}} \mathrm{s}$ in response to HI. To this end, we used the previously described Tric-GFP tool and showed that s- $\mathrm{LN}_{\mathrm{v}} \mathrm{Ca}^{2+}$ levels are indeed higher at HI than at LI.

We suggest that this $\mathrm{Ca}^{2+}$ increase reflects increased $s-\mathrm{LN}_{\mathrm{v}}$ activation by the $\mathrm{HB}$ eyelet and $\mathrm{HI}$ illumination. This interpretation is buttressed by the fact that $r h 6^{1}$ mutants retain a closed conformation of the s- $\mathrm{LN}_{\mathrm{v}}$ dorsal projections, which is known to reflect relatively low s- $\mathrm{LN}_{\mathrm{v}}$ activity (Fernández et al., 2008).

$s-\mathrm{LN}_{\mathrm{v}}$ activation leads to release of neuropeptides/neurotransmitters at its axonal terminals. This also explains the behavioral phenotype of $r h 6^{1}$ mutants: as described previously, they show a reduced M-peak amplitude and an advanced E-peak timing (Schlichting et al., 2014). The latter is present even more strongly in the complete loss-of-function $p d f^{01}$ mutant strain (Renn et al., 1999). This suggests that $r h 6^{1}$ mutant phenotype resembles that of a partial PDF loss-of-function; that is, the $s-\mathrm{LN}_{\mathrm{v}}$ s do not release as much PDF in the dorsal brain as WT flies, as evident by still high PDF staining intensity in the dorsal brain of $r h 6^{1}$ mutants in the middle of the day.

Circadian second messengers have previously been implicated in PER expression/stabilization, especially downstream of PDF signaling (Li et al., 2014). We therefore investigated changes of s-LN $\mathrm{v}_{\mathrm{v}}$ PER and TIM cycling in HI versus LI. Whereas TIM expression was not detectably different between the two conditions, PER staining was enhanced and shifted into the daytime by HI, consistent with PER stabilization. This delay of the PER staining profile nicely correlates with the $\sim 1$ h delayed onset of the E activity. The response to $\mathrm{HI}$ also fits with observations under long photoperiods: If one compares PER and TIM cycling in LD 12:12 and LD 18:6, only the maximum of PER staining intensity is significantly delayed under long day conditions. The E activity peak is similarly delayed (Menegazzi et al., 2013). Although this suggests that a similar mechanism regulates the integration of light intensity and exposure to long photoperiods, the molecular relationship between the PER cycle and behavior is unknown and awaits further study.

\section{References}

Abruzzi KC, Zadina A, Luo W, Wiyanto E, Rahman R, Guo F, Shafer O, Rosbash M (2017) RNA-seq analysis of Drosophila clock and non-clock neurons reveals neuron-specific cycling and novel candidate neuropeptides. PLoS Genet 13:e1006613. CrossRef Medline
Allada R, White NE, So WV, Hall JC, Rosbash M (1998) A mutant Drosophila homolog of mammalian clock disrupts circadian rhythms and transcription of period and timeless. Cell 93:791-804. CrossRef Medline

Benito J, Houl JH, Roman GW, Hardin PE (2008) The blue-light photoreceptor CRYPTOCHROME is expressed in a subset of circadian oscillator neurons in the Drosophila CNS. J Biol Rhythms 23:296-307. CrossRef Medline

Berson DM, Dunn FA, Takao M (2002) Phototransduction by retinal ganglion cells that set the circadian clock. Science 295:1070-1073. CrossRef Medline

Bonini NM, Leiserson WM, Benzer S (1993) The eyes absent gene: genetic control of cell survival and differentiation in the developing Drosophila eye. Cell 72:379-395. CrossRef Medline

Cook T, Pichaud F, Sonneville R, Papatsenko D, Desplan C (2003) Distinction between color photoreceptor cell fates is controlled by prospero in Drosophila. Dev Cell 4:853-864. CrossRef Medline

Daan S, Tinbergen J (1980) Young guillemots (Uria lomvia) leaving arctic breeding cliffs: a daily rhythm in numbers and risk. Ardea 67:96-100.

DeCoursey PJ, Walker JK, Smith SA (2000) A circadian pacemaker in freeliving chipmunks: essential for survival? J Comp Physiol A 186:169-180. CrossRef Medline

Depetris-Chauvin A, Berni J, Aranovich EJ, Muraro NI, Beckwith EJ, Ceriani MF (2011) Adult-specific electrical silencing of pacemaker neurons uncouples molecular clock from circadian outputs. Curr Biol 21:1783-1793. CrossRef Medline

Dolezelova E, Dolezel D, Hall JC (2007) Rhythm defects caused by newly engineered null mutations in Drosophila's cryptochrome gene. Genetics 177:329-345. CrossRef Medline

Ebihara S, Tsuji K (1980) Entrainment of the circadian activity rhythm to the light cycle: effective light intensity for a zeitgeber in the retinal degenerate $\mathrm{C} 3 \mathrm{H}$ mouse and the normal C57BL mouse. Physiol Behav 24:523527. CrossRef Medline

Fernández MP, Berni J, Ceriani MF (2008) Circadian remodeling of neuronal circuits involved in rhythmic behavior. PLoS Biol 6:e69. CrossRef Medline

Foster RG, Helfrich-Förster C (2001) The regulation of circadian clocks by light in fruitflies and mice. Philos Trans R Soc Lond B Biol Sci 356:17791789. CrossRef Medline

Gao XJ, Riabinina O, Li J, Potter CJ, Clandinin TR, Luo L (2015) A transcriptional reporter of intracellular $\mathrm{Ca}(2+)$ in Drosophila. Nat Neurosci 18:917-925. CrossRef Medline

Glaser FT, Stanewsky R (2005) Temperature synchronization of the Drosophila circadian clock. Curr Biol 15:1352-1363. CrossRef Medline

Golombek DA, Rosenstein RE (2010) Physiology of circadian entrainment. Physiol Rev 90:1063-1102. CrossRef Medline

Grima B, Chélot E, Xia R, Rouyer F (2004) Morning and evening peaks of activity rely on different clock neurons of the Drosophila brain. Nature 431:869-873. CrossRef Medline

Guo F, Yu J, Jung HJ, Abruzzi KC, Luo W, Griffith LC, Rosbash M (2016) Circadian neuron feedback controls the Drosophila sleep-activity profile. Nature 536:292-297. CrossRef Medline

Guo F, Chen X, Rosbash M (2017) Temporal calcium profiling of specific circadian neurons in freely moving flies. Proc Natl Acad Sci U S A 114: E8780-E8787. CrossRef Medline

Hardin PE, Hall JC, Rosbash M (1990) Feedback of the Drosophila period gene product on circadian cycling of its messenger RNA levels. Nature 343:536-540. CrossRef Medline

Hattar S, Liao HW, Takao M, Berson DM, Yau KW (2002) Melanopsincontaining retinal ganglion cells: architecture, projections, and intrinsic photosensitivity. Science 295:1065-1070. CrossRef Medline

Helfrich-Förster C, Winter C, Hofbauer A, Hall JC, Stanewsky R (2001) The circadian clock of fruit flies is blind after elimination of all known photoreceptors. Neuron 30:249-261. CrossRef Medline

Helfrich-Förster C, Edwards T, Yasuyama K, Wisotzki B, Schneuwly S, Stanewsky R, Meinertzhagen IA, Hofbauer A (2002) The extraretinal eyelet of Drosophila: development, ultrastructure, and putative circadian function. J Neurosci 22:9255-9266. CrossRef Medline

Helfrich-Förster C, Shafer OT, Wülbeck C, Grieshaber E, Rieger D, Taghert P (2007) Development and morphology of the clock-gene-expressing lateral neurons of Drosophila melanogaster. J Comp Neurol 500:47-70. CrossRef Medline 
Hofbauer A, Buchner E (1989) Does Drosophila have seven eyes? Naturwissenschaften 76:335-336. CrossRef

Kumar JP, Ready DF (1995) Rhodopsin plays an essential structural role in Drosophila photoreceptor development. Development 121:4359-4370. Medline

Lall GS, Revell VL, Momiji H, Al Enezi J, Altimus CM, Güler AD, Aguilar C, Cameron MA, Allender S, Hankins MW, Lucas RJ (2010) Distinct contributions of rod, cone, and melanopsin photoreceptors to encoding irradiance. Neuron 66:417-428. CrossRef Medline

Liang X, Holy TE, Taghert PH (2017) A series of suppressive signals within the Drosophila circadian neural circuit generates sequential daily outputs. Neuron 94:1173-1189.e4. CrossRef Medline

Li Y, Guo F, Shen J, Rosbash M (2014) PDF and cAMP enhance PER stability in Drosophila clock neurons. Proc Natl Acad Sci U S A 111:E1284E1290. CrossRef Medline

Lucas RJ, Lall GS, Allen AE, Brown TM (2012) How rod, cone, and melanopsin photoreceptors come together to enlighten the mammalian circadian clock. Prog Brain Res 199:1-18. CrossRef Medline

Malpel S, Klarsfeld A, Rouyer F (2002) Larval optic nerve and adult extraretinal photoreceptors sequentially associate with clock neurons during Drosophila brain development. Development 129:1443-1453. Medline

Menegazzi P, Vanin S, Yoshii T, Rieger D, Hermann C, Dusik V, Kyriacou CP, Helfrich-Förster C, Costa R (2013) Drosophila clock neurons under natural conditions. J Biol Rhythms 28:3-14. CrossRef Medline

Muraro NI, Ceriani MF (2015) Acetylcholine from visual circuits modulates the activity of arousal neurons in Drosophila. J Neurosci 35:1631516327. CrossRef Medline

Ogueta M, Hardie RC, Stanewsky R (2018) Non-canonical phototransduction mediates synchronization of the Drosophila melanogaster circadian clock and retinal light responses. Curr Biol 28:1725-1735.e3. CrossRef Medline

Pollack I, Hofbauer A (1991) Histamine-like immunoreactivity in the visual system and brain of Drosophila melanogaster. Cell Tissue Res 266:391398. CrossRef Medline

Ren GR, Folke J, Hauser F, Li S, Grimmelikhuijzen CJ (2015) The A- and B-type muscarinic acetylcholine receptors from Drosophila melanogaster couple to different second messenger pathways. Biochem Biophys Res Commun 462:358-364. CrossRef Medline

Renn SC, Park JH, Rosbash M, Hall JC, Taghert PH (1999) A pdf neuropeptide gene mutation and ablation of PDF neurons each cause severe abnormalities of behavioral circadian rhythms in Drosophila. Cell 99:791-802. CrossRef Medline

Rieger D, Stanewsky R, Helfrich-Förster C (2003) Cryptochrome, compound eyes, Hofbauer-Buchner eyelets, and ocelli play different roles in the entrainment and masking pathway of the locomotor activity rhythm in the fruit fly Drosophila melanogaster. J Biol Rhythms 18:377-391. CrossRef Medline

Rutila JE, Suri V, Le M, So WV, Rosbash M, Hall JC (1998) CYCLE is a second bHLH-PAS clock protein essential for circadian rhythmicity and transcription of Drosophila period and timeless. Cell 93:805-814. CrossRef Medline

Saint-Charles A, Michard-Vanhée C, Alejevski F, Chélot E, Boivin A, Rouyer F (2016) Four of the six Drosophila rhodopsin-expressing photoreceptors can mediate circadian entrainment in low light. J Comp Neurol 524: 2828-2844. CrossRef Medline

Sandrelli F, Tauber E, Pegoraro M, Mazzotta G, Cisotto P, Landskron J, Stanewsky R, Piccin A, Rosato E, Zordan M, Costa R, Kyriacou CP (2007) A molecular basis for natural selection at the timeless locus in Drosophila melanogaster. Science 316:1898-1900. CrossRef Medline
Schlichting M, Helfrich-Förster C (2015) Photic entrainment in Drosophila assessed by locomotor activity recordings. Methods Enzymol 552:105123. CrossRef Medline

Schlichting M, Grebler R, Peschel N, Yoshii T, Helfrich-Förster C (2014) Moonlight detection by Drosophila's endogenous clock depends on multiple photopigments in the compound eyes. J Biol Rhythms 29:75-86. CrossRef Medline

Schlichting M, Grebler R, Menegazzi P, Helfrich-Förster C (2015) Twilight dominates over moonlight in adjusting Drosophila's activity pattern. J Biol Rhythms 30:117-128. CrossRef Medline

Schlichting M, Menegazzi P, Lelito KR, Yao Z, Buhl E, Dalla Benetta E, Bahle A, Denike J, Hodge JJ, Helfrich-Förster C, Shafer OT (2016) A neural network underlying circadian entrainment and photoperiodic adjustment of sleep and activity in Drosophila. J Neurosci 36:9084-9096. CrossRef Medline

Schmid B, Helfrich-Förster C, Yoshii T (2011) A new ImageJ plug-in "ActogramJ” for chronobiological analyses. J Biol Rhythms 26:464-467. CrossRef Medline

Sehgal A, Price JL, Man B, Young MW (1994) Loss of circadian behavioral rhythms and per RNA oscillations in the Drosophila mutant timeless. Science 263:1603-1606. CrossRef Medline

Seluzicki A, Flourakis M, Kula-Eversole E, Zhang L, Kilman V, Allada R (2014) Dual PDF signaling pathways reset clocks via TIMELESS and acutely excite target neurons to control circadian behavior. PLoS Biol 12:e1001810. CrossRef Medline

Shang Y, Griffith LC, Rosbash M (2008) Light-arousal and circadian photoreception circuits intersect at the large PDF cells of the Drosophila brain. Proc Natl Acad Sci U S A 105:19587-19594. CrossRef Medline

Sivachenko A, Li Y, Abruzzi KC, Rosbash M (2013) The transcription factor Mef2 links the Drosophila core clock to Fas2, neuronal morphology, and circadian behavior. Neuron 79:281-292. CrossRef Medline

Sprecher SG, Desplan C (2008) Switch of rhodopsin expression in terminally differentiated Drosophila sensory neurons. Nature 454:533-537. CrossRef Medline

Stanewsky R, Frisch B, Brandes C, Hamblen-Coyle MJ, Rosbash M, Hall JC (1997) Temporal and spatial expression patterns of transgenes containing increasing amounts of the Drosophila clock gene period and a lacZ reporter: mapping elements of the PER protein involved in circadian cycling. J Neurosci 17:676-696. CrossRef Medline

Stanewsky R, Kaneko M, Emery P, Beretta B, Wager-Smith K, Kay SA, Rosbash M, Hall JC (1998) The cryb mutation identifies cryptochrome as a circadian photoreceptor in Drosophila. Cell 95:681-692. CrossRef Medline

Stoleru D, Peng Y, Agosto J, Rosbash M (2004) Coupled oscillators control morning and evening locomotor behaviour of Drosophila. Nature 431: 862-868. CrossRef Medline

Veleri S, Rieger D, Helfrich-Förster C, Stanewsky R (2007) Hofbauerbuchner eyelet affects circadian photosensitivity and coordinates TIM and PER expression in Drosophila clock neurons. J Biol Rhythms 22:29_ 42. CrossRef Medline

Vinayak P, Coupar J, Hughes SE, Fozdar P, Kilby J, Garren E, Yoshii T, Hirsh J (2013) Exquisite light sensitivity of Drosophila melanogaster cryptochrome. PLoS Genet 9:e1003615. CrossRef Medline

Yamaguchi S, Wolf R, Desplan C, Heisenberg M (2008) Motion vision is independent of color in Drosophila. Proc Natl Acad Sci U S A 105:49104915. CrossRef Medline

Yoshii T, Todo T, Wülbeck C, Stanewsky R, Helfrich-Förster C (2008) Cryptochrome is present in the compound eyes and a subset of Drosophila's clock neurons. J Comp Neurol 508:952-966. CrossRef Medline 